\title{
Erratum to: Environmental Applications Based on Birnbaum-Saunders Models
}

\author{
Víctor Leiva and Helton Saulo
}

\section{Erratum to:}

\section{Chapter 14 in: A. Adhikari et al. (eds.), Mathematical} and Statistical Applications in Life Sciences and Engineering https://doi.org/10.1007/978-981-10-5370-2_14

The original version of the book was inadvertently published with incorrect affiliations in Chapter 14

V. Leiva

Avenida Brasil 2241, Valparaíso 2362807, Chile

e-mail: victorleivasanchez@gmail.com

which have been corrected as

V. Leiva

School of Industrial Engineering, Pontificia Universidad católica de Valparaíso, Avenida Brasil 2241, Valparaíso 2362807, Chile

e-mail: victorleivasanchez@gmail.com 